\title{
Comparative Evaluation of Open Method and Laparoscopic Technique of Appendicectomy
}

\author{
Shri Krishna Ranjan ${ }^{1}$,Santosh Kumar ${ }^{2}$ \\ ${ }^{1}$ Associate Professor, Department of Surgery, Anugrah Narayan Magadh Medical College and Hospital,Gaya, ${ }^{2}$ Assisstant Professor, Department of \\ Surgery, Anugrah Narayan Magadh Medical College and Hospital, Gaya.
}

\section{Abstract}

Background: Most commonly performed abdominal surgery is appendicectomy open appendectomy (OA) was introduced by Mcburney in 1884 still it is the operation of choice in acute appendicitis. Laparoscopic appendectomy (LA) thoughwidely practiced, has not gained universal approval. LA was first described in 1983. Recent studies showed overall benefit in favor of LA. Aim: This study is done to view the therapeutic benefit of LA by comparing with conventional OA. Subjects and Methods: It is a prospective study in 103 patients who underwent appendicectomy from January 2019 to September 2019. Out of them 60 had conventional OA and 43 had LA. We compared the mean operation time, timeof adequateoral feeding, analgesic requirement, and duration of post-operative hospital stay. Results: We found that mean operation time was $33 \pm 5.8$ minute foropen appendicectomy and $47 \pm 7.5$ minute for laparoscopic appendicectomy. Duration of postoperative hospital stay was 1.2 days shorter in Laparoscopic group. LA required 1.1 shots of less analgesic than OA. Oral feeding was resumed 21 hours earlier following LA compared to OA. We also found that, in female patient, concurrent ovarian cysts, tubal pregnancy can be diagnosed and managed laparoscopically in the same sitting. Conclusion: Our study found that laparoscopic appendectomy is an effective and safe procedure irrespective sex of the patient. LA has added advantage of early return of bowel movement, less post-op hospital stay and less requirement of analgesic.

Keywords: Appendicitis, Laparoscopic appendectomy, Open appendectomy.

Corresponding Author: Dr. Santosh Kumar, Assistant Professor, Department of surgery, Anugrah Narayan Magadh Medical College and Hospital, Gaya.

Received: October 2019

Accepted: October 2019

\section{Introduction}

Appendicitis is the most common cause of acute abdomen, generally requiring urgent surgical intervention, with a lifetime incidence between $7 \%$ to $9 \% .^{[1]}$ Open appendectomy (OA), as described by McBurney in 1884, remained the gold standard for the treatment of acute appendicitis for more than a century. ${ }^{[2]}$ In 1983, laparoscopic appendicectomy (LA) was first described by Semm, a German surgeon since then, this approach has gained popularity. ${ }^{[3]}$ More than two decades later, the benefits of LA are still controversial. Despite numerous randomized trials several meta-analyses and systematic critical reviews comparing the two techniques, the relative advantages of each procedure have yet to be established. ${ }^{[4-12]}$ The European Association of Endoscopic Surgeons (EAES) has recently released guidelines on appendectomy that clearly favor the laparoscopic approach. ${ }^{[13]}$ It is better to minimize the wound and benefit the advantages of minimally invasive procedure. Common advantages of laparoscopic appendectomy are: less postoperative pain, short hospital stay, quicker return of bowel function, quicker return to normal activity and better cosmetic results. ${ }^{[3]}$

The aim of this study was to compare the outcomes in terms of duration of surgery, length of hospital stay, and postoperative complications for the Open method and the Laparoscopic method of appendicectomy.

\section{Subjects and Methods}

This prospective study was conducted at ANMMCh, Gaya duration from January 2019 to September 2019. The study was approved by the institutional research committee. The participating patients were informed about the procedure and consent was taken from the subjects before starting the procedure. A total of 103 patients participated in the study. The subjects themselves opted for the mode of surgery.

Pre-operative diagnosis was made using history, clinical examination coupled with laboratory findings and imaging studies. In open group, only appendix removed via McBurney's incision was included in the study. Patients in whom midline incisions were given were excluded from the study. Operating time was calculated from the time of first incision up to the placement of last stitch on the closing wound. Post-operative hospital stay, in days, was defined as the time the patient left the operation 
theatre up to the time of discharge from the hospital. Number of shots of injectable analgesics given to the patients postoperatively was recorded. Time of resumption of oral food, in hours, was calculated from the time of surgery..

For the laparoscopic approach, a $10-\mathrm{mm}$ trocar was placed at the umbilicus and 2 additional $5 \mathrm{~mm}$ trocars were inserted in the lower abdomen and right hypochondrium respectively (Figure 1). The mesoappendix was transected after coagulation with bipolar cautery. The base of the appendix was ligated with an end loop constructed with a Roeder's knot on a No-1 vicryl thread (Figure 2). Usually two end loops were used. The specimens were removed via the $5 \mathrm{~mm}$ port in hypogastrium. In case of peritoneal collection suction irrigation was used. In open approach, we used traditional Grid -Iron incision over the Mc-Burney's point. The appendix bases were ligated with barbar thread. Appendix base was not invaginated. All patients received preoperative and post-operative antibiotic. A combination of 2nd or 3rd generation cephalosporin and metronidazole were used. In presence of severe systemic sign an aminoglycoside, usually Amikacin was added. All patients were discharged on resumption of solid food and complete remission of fever.

Patients with severe cardiopulmonary disease, pregnancy, generalized peritonitis were excluded from the study.

Furthermore, patients who were chosen to undergo laparoscopic appendicectomy but had contraindication i.e. ASA IV and physiologically compromised having to creation of carbon dioxide were also exclude from the study. Some patients have refused to undergo operation because of personal problems and financial problems and refused to give consent were also excluded from the study.

The data was tabulated and was subjected to statistical analysis using SPSS (Statistical Package for the Social Sciences) version 10.0.

\section{Results}

During study period, total 103 appendectomy were performed, of which 60 were open and 43 were laparoscopic. Ages of thepatients ranged from 18 to 50 years. Demographic profile of the patients is given in Table 1.

Table 1: Demographic profile of the patients. $(n=103)$

\begin{tabular}{|l|l|l|}
\hline Variable & LA $(\mathbf{n}=\mathbf{4 3})$ & OA $(\mathbf{n}=\mathbf{6 0})$ \\
\hline Mean age (Years) & 34.9 & 35.4 \\
\hline Sex ratio (F:M) & $17: 26$ & $27: 33$ \\
\hline
\end{tabular}

Table 2: Comparison between open verses laparoscopic appendicectomy.

\begin{tabular}{|l|l|l|l|}
\hline Outcome & LA & OA & p-value \\
\hline Operating time (in minute) & $47 \pm 7.5$ & $33 \pm 5.8$ & \\
\hline Number of analgesic dose & 2 & 3.1 & $<0.001$ \\
\hline $\begin{array}{l}\text { Resumption of oral food in } \\
\text { hours }\end{array}$ & 38 & 59 & \\
\hline Hospital stay in days & 3.2 & 4.4 & $<0.001$ \\
\hline Wound infection & 1 & 11 & $<0.001$ \\
\hline
\end{tabular}

Operating time in laparoscopic appendicectomy (LA) was $47 \pm 7.5$ minutes and in open appendicectomy (OA) was
$33 \pm 5.8$ minute.

Table 3: Concomitant pathology in laparoscopy group.

\begin{tabular}{|l|l|}
\hline Ectopic pregnancy & 1 case \\
\hline Ovarian cystectomy & 4 cases \\
\hline Peritoneal biopsy & 2 cases \\
\hline
\end{tabular}

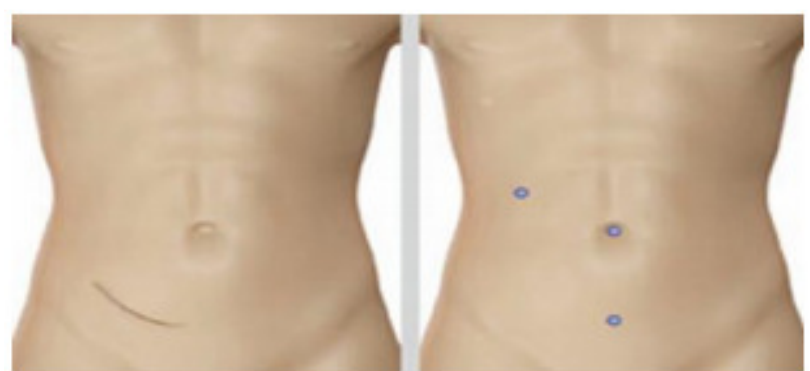

Figure 1: Incision site in open and laparoscopic method

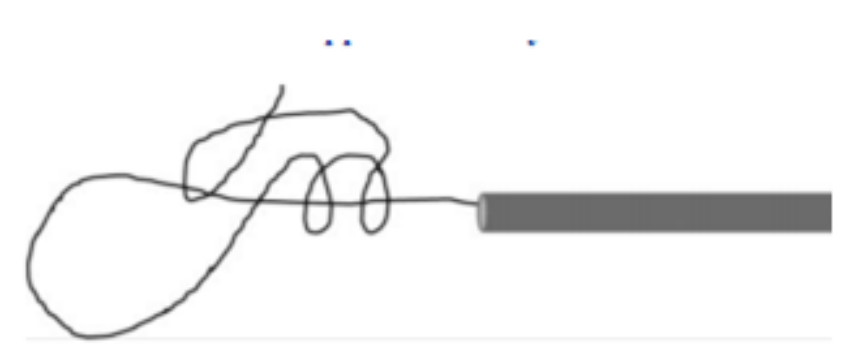

Figure 2: Roeder's Knot

\section{Discussion}

During the past two decades, general surgery has seen a major shift from open to minimally invasive surgery. Although classic open appendectomy is simple and effective, it has some drawbacks like wound infection, painful, and delayed recovery. Laparoscopic appendectomy is another option which appears to have advantages over the open method since it uses smaller incision for access and allows clearer and wider vision with a camera. Although the incision is smaller, thebenefits are still not clear. One should always think of laparoscopic surgery and open as being complimentary to each other. The advantages claimed by several studies are shorter hospital stay, decreased mortality rates, quicker return to work and lower hospital cost. ${ }^{[12]}$

However, the controversy still continues about these advantages and laparoscopic appendectomy has not replaced the open method as laparoscopic cholecystectomy has done. ${ }^{11}$ All patients were explained about both the procedures, and the approach was based on patient's preference. The mean operative time of LA was 21.9 minute longer than OA. Other authors have also reported similar results. ${ }^{[14,15]}$

In this study, one patient had post-operative complication in LA group whereas 11 patients in OA group. Most of the morbidities were due to wound infection. Wound infection rate in the open surgery group was higher than LA group. In one study it has highlighted that the difference in wound complication rates is a major benefit of laparoscopic appendicectomy. ${ }^{[16]}$ There was significant decrease in the length of hospital stay in patients 
undergoing LA $(p<0.001)$, Vallina et $\mathrm{al}^{[17]}$ found the average total cost of LAs to be $30 \%$ greater than that of conventional OAs. In this hospital, there was no operation cost difference between the two groups, but the cost would be more based on the duration of hospital stay, making laparoscopy procedures more cost effective. However laparoscopic approach still has to prove its efficacy and safety in clinical trials.

\section{Conclusion}

Laparoscopic appendectomy is an effective and safe option and the procedure of choice for patient with increased BMI. It is particularly advantageous in patient in whom appendicitis diagnosis is in dilemma it has minimal complications and less hospital stays and has the advantage of managing concomitant pathologies.

\section{References}

1. Addiss DG, Shaffer N, Fowler BS, Tauxe RV. The epidemiology of appendicitis and appendectomy in the United States. Am JEpidemiol. 1990;132:910- 25.

2. McBurney $\mathrm{C}$. The incision made in the abdominal wall in cases of appendicitis, with a description of a new method of operating. Ann Surg. 1894;20:38-43.

3. Semm K: Endoscopic appendectomy. Endoscopy. 1983;15:59-64.

4. Katkhouda N, Mason RJ, Towfigh S, Gevorgyan A, Essani R. Laparoscopic versus open appendectomy: A prospective randomized double-blind study. Ann Surg. 2005;242:439-48.

5. Omli S, Magnone S, Bertolinin A, Croce E. Laparoscopic versus open appendectomy in acute appendicitis: A randomized prospective study. SurgEndosc. 2005;19:1193-5.

6. Moberg AC, Berndsen F, Palmquist I, Petersson U, Resch T, Montgomery A. Randomized clinical trial of laparoscopic versus open appendicectomy for confirmed appendicitis. Br J Surg. 2005;92:298-304

7. Sauerland S, Lefering R, Holthausen U, Neugebauer EA. Laparoscopic vs. conventional appendectomy - a meta-analysis of randomised controlled trials. Langenbecks Arch Surg. 1998:383:289-95.

8. Chung RS, Rowland DY, Li P, Diaz J. A meta-analysis of randomized controlled trials of laparoscopic versus conventional appendectomy. Am J Surg. 1999;177:250-6.

9. Garbutt JM, Soper NJ, Shannon WD, Botero A, Littenberg B. Meta-analysis of randomized controlled trials comparing laparoscopic and open appendectomy. SurgLaparoscEndosc 1999;9:17-26.

10. Golub R, Siddiqui F, Pohl D. Laparoscopic versus open appendectomy: A meta-analysis. J Am Coll Surg. 1998;86:545-53.

11. Fingerhut A, Millat B, Borrie F. Laparoscopy versus open appendectomy: Time to decide. World J Surg. 1999;23:835-45.

12. Sauerland S, Lefering R, Neugebauer EA. Laparoscopic versus open surgery for suspected appendicitis. Cochrane DatabaseSyst Rev. 2007;4:CD001546.

13. Vettoretto N, Gobbi S, Corradi A. Consensus conference on laparoscopic appendectomy: development of guidelines. Colorectal Dis. Jul 2011;13(7):748-54.

14. Moberg AC, Montgomery A. Appendicitis: laparoscopic versus conventional operation: a study and review of literature. SurgLaparoscEndosc. 1997; 7:459-63.

15. Temple LK, Litwin DE, McLoid RS. A meta-analysis of laparoscopic versus open appendectomy in patients suspected of having acute appendicitis. Can J Surg. 1999;42:377-83.

16. Tate JJT. Laparoscopic appendectomy. Br J Surg. 1996;83:116970. 17. Vallina VL, Velasco JM, McCulloch CS. Laparoscopic versus conventional appendectomy. Ann Surg. 1993;218:685-92.

Copyright: (C) the author(s), 2019. It is an open-access article distributed under the terms of the Creative Commons Attribution License (CC BY 4.0), which permits authors to retain ownership of the copyright for their content, and allow anyone to download, reuse, reprint, modify, distribute and/or copy the content as long as the original authors and source are cited.

How to cite this article: Ranjan SK, Kumar S.Comparative Evaluation of Open Method and Laparoscopic Technique of Appendicectomy. Acad. J Surg. 2019;2(2):20-22.

DOI: dx.doi.org/10.21276/ajs.2019.2.2.5

Source of Support: Nil, Conflict of Interest: None declared. 